\title{
Comparison between Fine Needle Aspiration Cytology of Thyroid Nodules and Histology after Surgical Excision
}

\author{
Ibrahim Alali ${ }^{*}$, Sleiman Khalil ${ }^{2}$ and Younes Kabalan ${ }^{1}$ \\ ${ }^{1}$ Endocrinology Department, Al-Assad University Hospital, Damascus University, Syria \\ ${ }^{2}$ Pathology Department, Al-Assad University Hospital, Damascus University, Syria
}

*Corresponding author: Ibrahim Alali, Endocrinology Department, Al-Assad University Hospital, Damascus University, Syria, Tel: 00963932883578; E-mail: Ibali2012@gmail.com

Received: 21 Dec, 2018 | Accepted: 17 Jan, 2019 | Published: 22 Jan, 2019

Citation: Alali I, Khalil S, Kabalan Y (2019) Comparison between Fine Needle Aspiration Cytology of Thyroid Nodules and Histology after Surgical Excision. Int J Endocrinol Metab Disord 5(1): dx.doi.org/10.16966/2380-548X.152

Copyright: (c) 2019 Alali I, et al. This is an open-access article distributed under the terms of the Creative Commons Attribution License, which permits unrestricted use, distribution, and reproduction in any medium, provided the original author and source are credited.

\begin{abstract}
Background: Thyroid nodules are an extremely common disorder. Fine Needle Aspiration (FNA) is the gold standard procedure for thyroid nodules diagnosis and management; it helps clinicians to make a proper therapeutic decision and minimizes the need for unnecessary surgery.

Objective: To assess thyroid FNA sensitivity, specificity, accuracy, Positive Predictive Value (PPV), and Negative Predictive Value (NPV) in Al-Assad University Hospital using the Bethesda system for reporting thyroid cytology.

Methods: We prospectively followed thyroid FNAs, then the histological results were followed after performing surgery. FNA was performed by endocrinologists in al-Assad and al-Mouwassat university hospitals, and the cytological study for all samples was performed in pathology department at al-Assad university hospital. All available data were analyzed with SPSS version 23 statistical program.

Results: A total of 381 nodules from 324 patients, 281 women (86.7\%), aged between 13-80 years (46.1 \pm 13.01$)$ had FNA. There were 26(6.8\%), $216(56.7 \%), 52(13.6 \%), 44(11.5 \%), 30(7.9 \%)$, and $13(3.4 \%)$ nodules in categories unsatisfactory, benign, Atypia of undetermined significance/ Follicular lesion of undetermined significance AUS/FLUS, Follicular neoplasm/Suspicious for Follicular Neoplasm (FN)/(SFN) Suspicious for Malignancy, and malignant, respectively. Histology was obtained for 172 nodules, sensitivity, specificity, PPV, NPV, and accuracy were $85 \%$, $79.35 \%$, $47.22 \%, 96.05 \%$ and $80.36 \%$, respectively. Malignancy rate in unsatisfactory, AUS/FLUS, and FN/SFN cytology was $0 \%$, 9.1\%, and 6.5\%, respectively.

Conclusion: Specificity was slightly lower than anticipated based on global data and so did the PPV that may be due to the trend of overestimating cellular irregularity, however fine needle aspiration biopsy remains an accurate procedure in excluding malignancy due to its high sensitivity and NPV.
\end{abstract}

Keywords: Bethesda; Thyroid nodules; Fine needle aspiration; Accuracy

\section{Introduction}

Thyroid nodules are extremely common; they are detected in about $4 \%$ of the population by palpation and their prevalence rises to as high as $67 \%$ when screened by ultrasonography $[1,2]$.

Thyroid cancer is rare. While the most recent available data from cancer registry in Syria have estimated thyroid cancer prevalence in Syrian adults diagnosed with cancer in 2008 by $7 \%$ and $2 \%$ in women and men respectively, [3] the 2015 American National Cancer Institute (NCI) report estimated thyroid cancer by $3.1 \%$ of all new cancer cases with a $98.1 \%$ surviving 5 years [4].

Consequently, excluding malignancy in thyroid nodules is crucial. Among all available means used for thyroid nodules management, Fine Needle Aspiration (FNA) biopsy proved to be a safe, inexpensive, uncomplicated procedure that, when handled by an experienced clinician, has a high diagnostic value [5-8].
Using a proper terminology system for reporting thyroid cytology is essential for achieving the accurate diagnosis and minimizing the false negative and positive rates. The Bethesda System for Reporting Thyroid Cytology (TBSRTC) is one of the most commonly used systems [9-11], and it is adopted by the American Thyroid Association [8].

In this article, the fine needle aspiration cytology results were compared with histology after thyroidectomy or lobectomy to determine the accuracy of this procedure at our institute, we also tried to figure out the possible reasons behind the discrepancy between cytological and histological diagnosis.

\section{Methods and Materials}

The study was performed between July 2016 and February 2018.

Patients who were included in the study were from visitors to 
endocrinology clinic in Al-Assad and Al-Mouwassat University Hospitals with thyroid nodules indicated for FNA according to the 2015 American Thyroid Association (ATA) guidelines [8].

Patients who came with a cytology report out of Al-Assad Hospital department of pathology were excluded from the study.

Fine needle aspiration biopsy was performed in an outpatient setting, with 21-23 gauge syringes guided by ultrasonography using one of two devices; Toshiba/Nemio/SSA-550A and LS6-14 linear probe Mindray/M7 Diagnostic Ultrasound System. FNA was done often in two passes at least for each nodule, after taking the aspiration it was spread on labeled slides ranged from two to ten slides, fixed immediately with alcohol $95 \%$ spray, then with alcohol $100 \%$ solution and stained with Hematoxylin and Eosin. All samples were read by pathologists at Al-Assad Hospital, and all specimens of cytology were classified into six categories according to the 2009 Bethesda System for reporting thyroid cytology [11].

Based on clinical data and FNA results, patients went into either surveillance or surgery in the light of 2015 ATA guidelines. In the majority of cases, histology samples were interpreted atour institute, and patients who had malignancy in histopathology that couldn't be determined if the malignant nodule was targeted by FNA or not were excluded from the study.

Statistical analysis was concerned with assessing FNA efficacy indicators including sensitivity, specificity, accuracy, Positive Predictive Value (PPV) and Negative Predictive Value (NPV). All available data were analyzed with SPSS V23 IBM software.

\section{Results}

Fine needle aspiration biopsy was accomplished for 381 nodules from 324 patients, $281(86.7 \%)$ of them were females with a female to male ratio of 6.53:1, results of cytology were as in table 1 .

After following FNA results a number of patients were sent into surgery based on cytology, clinical and radiological data. Thereafter, histology results were followed for 174 nodules after surgical excision, two of them were excluded because we couldn't assure that malignancy was from the nodule which was biopsied.

172 nodules from 147 patients, 131(89.1\%) of them were females, had been collected and results were as shown in table 2 .

Malignancy rate in unsatisfactory, benign, AUS/FLUS, FN/SFN, suspicious and malignant cytology was $0 \%, 3.9 \%, 9.1 \%, 6.5 \%, 29.2 \%$ and $83.3 \%$ respectively. Incidental micropapillary thyroid carcinomas were found in 6 patients $(4.08 \%)$ in all series three of them was

Table 1: Shows the Bethesda categories for FNA samples in our study.

\begin{tabular}{|l|c|c|}
\hline \multicolumn{1}{|c|}{ Cytology } & Number of nodules & Percentage \% \\
\hline Unsatisfactory & 26 & 6.8 \\
\hline Benign & 216 & 56.7 \\
\hline $\begin{array}{l}\text { Atypia of undetermined } \\
\text { significance/Follicular lesion of } \\
\text { undetermined significance }\end{array}$ & 52 & 13.6 \\
\hline $\begin{array}{l}\text { Follicular neoplasm/Suspicious } \\
\text { for follicular neoplasm }\end{array}$ & 44 & 11.5 \\
\hline Suspicious for Malignancy & 30 & 7.9 \\
\hline Malignant & 13 & 3.4 \\
\hline Total & 381 & 100 \\
\hline
\end{tabular}

accompanied with a primary thyroid cancer. Thyroid cancer prevalence in all surgical samples was $18.3 \%, 77.7 \%$ were PTC and $7.4 \%$ were FTC and $3.7 \%$ HCTC and $11.1 \%$ were MTC.

According to these results there were three negative aspirates proved to be malignant in histology (False Negative- FN) two of them were medullary carcinomas and the latter was papillary carcinoma, there were 19 positive aspirates proved to be benign in histology (false positive FP) 8 cases were follicular adenomas 7 cases were Hashimoto thyroiditis 3 cases were Hürthle cell adenomas and one case of subacute thyroiditis, True Positive (TP) and True Negative (TN) aspirates were 17 and 73 respectively.

In this study, there were 22 cases of AUS/FLUS with a histological diagnosis; $20(90.9 \%)$ were benign and one of them was papillary carcinoma while the last one was medullary carcinoma. Also, there were 31 cases with FN/SFN cytology underwent surgery and the majority of them $29(93.5 \%)$ were follicular adenomas, whereas two cases turned out to be papillary and follicular carcinomas.

Based on these numbers we calculated accuracy parameters of FNA after excluding unsatisfactory, AUS/FLUS, and FN/SFN from calculations because it was difficult to classify it as a benign or a malignant cytology:

$$
\begin{aligned}
& \text { Sensitivity }(\mathrm{TP} / \mathrm{TP}+\mathrm{FN})=17 /(17+3)=85 \% \\
& \text { Specificity }(\mathrm{TN} / \mathrm{TN}+\mathrm{FP})=73 /(73+19)=79.35 \%
\end{aligned}
$$$$
\text { Positive predictive value PPV }(\mathrm{TP} / \mathrm{TP}+\mathrm{FP})=17 /(17+19)=47.22 \%
$$

Negative predictive value NPV $(\mathrm{TN} / \mathrm{TN}+\mathrm{FN})=73 /(73+3)=96.05 \%$

$$
\text { Accuracy }(\mathrm{TN}+\mathrm{TP}) /(\mathrm{TP}+\mathrm{TN}+\mathrm{FP}+\mathrm{FN})(17+73) / 112=80.36 \%
$$

When we excluded the suspicious for malignancy category from accuracy calculations as a positive for malignancy, the results were as follows; sensitivity $76.9 \%$, specificity $97.33 \%$, PPV $83.33 \%$, NPV $96.05 \%$, and accuracy $94.32 \%$. This modified results highlighted the effect of Bethesda $\mathrm{V}$ category on accuracy parameters due to overestimating cellular and nuclear abnormalities.

\section{Discussion}

Due to progressive development in diagnosing thyroid lesions by using new imaging techniques and widespread use of FNA, thyroid cancer increased in prevalence but without changing prognosis [4].

Fine needle aspiration is the gold standard in the management of thyroid lesions and it helps to minimize the need for unnecessary surgeries [8,12], because FNA helps in making the surgical decision of total thyroidectomy or lobectomy with or without lymph node dissection where complication always are greater with total thyroidectomy and total neck dissection.

By using TBSRTC, thyroid cytology is interpreted in six categories; undiagnostic or unsatisfactory, benign, atypia or follicular lesion of undetermined significance, follicular or suspicious for follicular neoplasm, suspicious for malignancy, and malignant cytology. Each one of these categories has a risk of malignancy and proposes a particular management $[10,11]$.

In our study we performed FNA for 381 nodules from 324 patients; most of them were women as observed in most studies, cytologic results shown in table 1, comparison with other similar studies is shown in table 3 [13-16].

Unsatisfactory cytology was seen in $26(6.8 \%)$ of nodules similar to some studies $[14,15]$ but less than others, $[16]$ this interpretation is 
Table 2: Distribution of the cytology results according to final histology.

\begin{tabular}{|c|c|c|c|c|c|c|}
\hline Cytology & Unsatisfactory & Benign & AUS/FLUS & FN/SFN & Suspicious & Malignant \\
\hline \multicolumn{7}{|c|}{ Histology } \\
\hline Benign & 7 & 73 & 20 & 29 & 17 & 2 \\
\hline \multicolumn{7}{|c|}{ Malignant } \\
\hline PTC & 0 & 1 & 1 & 1 & 6 & 9 \\
\hline FTC & 0 & 0 & 0 & 1 & 1 & 0 \\
\hline НСТC & 0 & 0 & 0 & 0 & 0 & 1 \\
\hline MTC & 0 & 2 & 1 & 0 & 0 & 0 \\
\hline Total & 7 & 76 & 22 & 31 & 24 & 12 \\
\hline
\end{tabular}

PTC: Papillary Thyroid Carcinoma; FTC: Follicular Thyroid Carcinoma; HCTC: Hürthle Cell

Thyroid Carcinoma; MTC: Medullary Thyroid Carcinoma

Table 3: Bethesda Categories comparison with previous studies.

\begin{tabular}{|l|c|c|c|c|c|}
\hline $\begin{array}{c}\text { Bethesda Category } \mathbf{n} \\
\text { (\%) }\end{array}$ & This series & Hajmanoochehri F, et al. ${ }^{[13]}$ & Arul P, et al. ${ }^{[14]}$ & Sinna EA, et al. ${ }^{[15]}$ & Tepeoğlu M, et al. ${ }^{[16]}$ \\
\hline Bethesda 1 & $26(6.8)$ & $0(0)$ & $24(5)$ & $21(7.1)$ & $122(12)$ \\
\hline Bethesda 2 & $216(56.7)$ & $29(28.7)$ & $215(44.5)$ & $98(33.1)$ & $697(68.3)$ \\
\hline Bethesda 3 & $52(13.6)$ & $4(4)$ & $14(2.9)$ & $40(13.5)$ & $100(9.8)$ \\
\hline Bethesda 4 & $44(11.5)$ & $27(26.7)$ & $104(21.5)$ & $49(16.5)$ & $41(4)$ \\
\hline Bethesda 5 & $30(7.9)$ & $16(15.8)$ & $74(15.3)$ & $30(10.1)$ & $36(3.5)$ \\
\hline Bethesda 6 & $13(3.4)$ & $25(24.8)$ & $52(10.8)$ & $58(19.5)$ & $25(2.4)$ \\
\hline Total & $381(100)$ & $101(100)$ & $483(100)$ & $296(100)$ & $1021(100)$ \\
\hline
\end{tabular}

affected by the type of thyroid nodules solid or cystic, the experience of the aspirator, and the way followed in preparing samples [17]. Of these nodules, only 7 were sent into surgery based on ultrasonographic suspicion and they were benign since most of the nodules in this category are not sent to surgery, the accurate malignancy risk is unknown and estimated by $5-10 \%$ [11].

On the other hand, benign cytology was the most common category in this series 216 nodules (56.7\%) compared to 28 to $69 \%$ in other series [13-16], most of the nodules in this cytology were managed by clinical and radiological surveillance $[8,11]$, so a little portion was sent to surgery based on either nodule size (more than $4 \mathrm{~cm}$ ) or patient preference making it hard to estimate the exact risk of malignancy which is suggested by TBSRTC of 0-3\% [11]. Surgery was performed for 76 nodules in this category, three of them $(3.9 \%)$ proved to be malignant; one nodule was PTC and two were MTC, samples were reviewed and two of them may reflect a sampling error, while the third was a misinterpretation. Medullary thyroid carcinoma detection rate by FNA is only $50 \%$ of MTCs as published by Trimboli P, et al. [18] and that suggested the use of other techniques like calcitonin washout from nodules which raised the detection rate up to $100 \%$ [19].

The nuclear or architectural atypia may not be enough to make the diagnosis of malignancy so the FNA fall in the category AUS/FLUS which is indeterminate cytology hard to estimate a malignancy risk $\sim 10-30 \%$ due to different management plans [11]. In our study, this category comprised $13.6 \%$ of all FNAs similarly to some studies [15] but more than others $[13,14,16]$ with a malignancy rate of $9.1 \%$.

Nuclear changes either in shape or in contour without papillary carcinoma features may help categorize FNA as follicular neoplasm or suspicious for follicular neoplasm, but the definite diagnosis is made histologically after lobectomy or thyroidectomy, this category has an estimated risk of malignancy about 25-40\% [11].
There were 44 nodules (11.5\%) in this study less than other published series [13-15] with a surgical follow up of 31 (70\%) nodules showed that most of them 29(93.5\%) were benign and only two cases (6.5\%) were PTC and FTC and this malignancy rate was lower than results of several studies [13-16].

The most controversial category in our series was suspicious for malignancy which included 30(7.9\%) nodules with a surgical followup of $24(80 \%)$ nodules. malignancy rate in this category was $29.2 \%$ (6 cases were PTC and one case of FTC), the remaining nodules proved to be benign (6 lymphocytic thyroiditis, 8 follicular adenomas, 2 Hürthle cell adenomas, and one case of subacute thyroiditis). Consequently, these results made a low malignancy rate, this rate was lower than other studies [13-16], but a lower malignancy rate was seen in some series [20].

Improper fixation, poor FNA technique may cause nuclear changes in follicular cells resembles papillary carcinoma, [21] some thyroid lesions especially lymphocytic thyroiditis can exhibit a nuclear enlargement and contour irregularity with nuclear grooves giving a cytological picture of PTC [21,22]. Besides that, the cytopathologist should not ignore the nuclear changes just for the presence of thyroiditis in background because the coincidence of PTC with thyroiditis is not uncommon [22].

The diagnosis of Hürthle cell neoplasms is challenging and it is a source of false positive diagnosis even though there is often no important nuclear atypia [23].

The nuclei of follicular cells in follicular neoplasms could be hyperchromatic and a little larger than normal cells, any nuclear features suggest papillary carcinoma should be addressed as suspicious for malignancy or malignant cytology irrespective of microfollicular abundance [22].

Malignant cytology included 13 nodules with surgical results of $12(92.3 \%)$ nodules showed a benign result of two cases; lymphocytic 
Table 4: Comparison of accuracy parameters with previous studies.

\begin{tabular}{|l|c|c|c|}
\hline \multicolumn{1}{|c|}{ Study } & Year & Sensitivity \% & Specificity \% \\
\hline This series & Syria 2018 & 85 & 79.35 \\
\hline Hajmanoochehri F, et al. ${ }^{[13]}$ & Iran 2015 & 95.2 & 68.4 \\
\hline Arul P, et al. ${ }^{[14]}$ & India 2015 & 94.4 & 97.6 \\
\hline Sinna EA, et al. ${ }^{[15]}$ & Egypt 2012 & 94.2 & 95.14 \\
\hline${\text { Tepeoğlu M, et al. }{ }^{[16]}}$ & Turkey 2014 & 100 & 93.7 \\
\hline
\end{tabular}

thyroiditis and Hürthle cell adenoma, other cases were 9 papillary carcinomas and Hürthle cell carcinoma. Malignancy rate in this category $83.3 \%$ was lower than other reported series [13-16] where it reached $100 \%$ or the malignancy rate reported by TBSRTC (9799\%) [10].

Finally, FNA accuracy parameters differ among different studies according to the categories included as a positive for malignancy, some studies $[13-15,20]$ included indeterminate cytology, while our study and others [24] did not. False positive results lowered specificity in our study to $79.35 \%$ compared with other studies (68.4\%-97.6\%), results are summarized in table 4 , with a sensitivity of $85 \%$ compared with $(94.2 \%-100 \%)$, and total accuracy of $80.36 \%$ while other studies reported the accuracy of (85.14\%-97\%).

\section{Conclusion}

Reporting thyroid FNA could be affected anywhere during work, starting with aspiration and preparing slides until reading by cyto/ pathologist, so any error in this way may lead to improper results. Although this pitfall, FNA remains reliable, inexpensive, and an accurate procedure in diagnosing thyroid nodules.

\section{Acknowledgment}

We would like to thank all staff in Pathology Department at alAssad University Hospital, Damascus, Syria, for their cooperation.

\section{Disclosure}

The authors declare they have no potential conflict of interest with respect to this manuscript.

\section{Funding}

NIL

\section{References}

1. Dean DS, Gharib H (2008) Epidemiology of thyroid nodules. Best Pract Res Clin Endocrinol Metab 22: 901-911.

2. Russ G, Leboulleux S, Leenhardt L, Hegedüs L (2014) Thyroid incidentalomas: Epidemiology, risk stratification with ultrasound and workup. Eur Thyroid J 3: 154-163.

3. Masallati Ziad, Eljord Ahmad, Al Jerf Feras (2008) Cancer Incidence in Syria-cancer registry-Ministry of Health publication.

4. Cancer Stat Facts: Thyroid Cancer, National Cancer Institute.

5. Castro MR, Gharib H (2003) Thyroid Fine-Needle Aspiration Biopsy: Progress, Practice, and Pitfalls. Endocr Pract 9: 128-136.

6. Baloch ZW, LiVolsi VA (2004) Fine-Needle Aspiration of Thyroid Nodules: Past, Present, and Future. Endocr Pract 10: 234-241.

7. Layfiel LJ, Cibas ES, Gharib H, Mandel SJ (2009) Thyroid Aspiration Cytology: Current Status. CA Cancer J Clin 59: 99-110.

8. Haugen BR, Alexander EK, Bible KC, Doherty GM, Mandel SJ, et al. (2016) 2015 American Thyroid Association Management Guidelines for Adult Patients with Thyroid Nodules and Differentiated Thyroid Cancer: The American Thyroid Association Guidelines Task Force on Thyroid Nodules and Differentiated Thyroid Cancer. Thyroid 26: 1-133.

9. Wise O, Howard MR (2016) Thyroid cytology: a review of current international reporting systems and emerging developments. Cytopathology 27: 161-167.

10. Cibas ES, Ali SZ (2017) The 2017 Bethesda System for Reporting Thyroid Cytopathology. Thyroid 27: 1341-1346.

11. Cibas ES, Ali SZ (2009) The Bethesda System for Reporting Thyroid Cytopathology. Am J Clin Pathol 132: 658-665.

12. Gharib H, Papini E, Garber JR, Duick DS, Harrell RM, et al. (2016) American Association of Clinical Endocrinologists, American College of Endocrinology, and Associazione Medici Endocrinologi Medical Guidelines for Clinical Practice for the Diagnosis and Management of Thyroid Nodules--2016 Update. Endocr Pract 22: 622-639.

13. Hajmanoochehri F, Rabiee E (2015) FNAC accuracy in diagnosis of thyroid neoplasms considering all diagnostic categories of the Bethesda reporting system: A single-institute experience. J Cytol 32: 238-243.

14. Arul P, Masilamani S (2015) A correlative study of solitary thyroid nodules using the Bethesda system for reporting thyroid cytopathology. J Cancer Res Ther 11: 617-622.

15. Sinna EA, Ezzat N (2012) Diagnostic accuracy of fine needle aspiration cytology in thyroid lesions. J Egypt Natl Canc Inst 24: 63-70.

16. Tepeoğlu M, Bilezikçi B, Bayraktar SG (2014) A histological assessment of the Bethesda system for reporting thyroid cytopathology (2010) abnormal categories: a series of 219 consecutive cases. Cytopathology 25: 39-44.

17. Redman R, Zalaznick H, Mazzaferri EL, Massoll NA (2006) The Impact of Assessing Specimen Adequacy and Number of Needle Passes for Fine-Needle Aspiration Biopsy of Thyroid Nodules. Thyroid 16: 55-60.

18. Trimboli P, Treglia G, Guidobaldi L, Romanelli F, Nigri G, et al. (2015) Detection rate of FNA cytology in medullary thyroid carcinoma: a meta-analysis. Clin Endocrinol (Oxf) 82: 280-285.

19. Trimboli P, Guidobaldi L, Bongiovanni M, Crescenzi A, Alevizaki $M$, et al. (2016) Use of Fine-Needle Aspirate Calcitonin to Detect Medullary Thyroid Carcinoma a Systematic Review. Diagn Cytopathol 44: 45-51.

20. Sellami M, Tababi S, Mamy J, Zainine R, Charfi A, et al. (2011) Interest of fine-needle aspiration cytology in thyroid nodule. Eur Ann Otorhinolaryngol Head Neck Dis 128: 159-164.

21. Baloch ZW, Livolsi VA (2006) Cytologic and Architectural Mimics of Papillary Thyroid Carcinoma Diagnostic Challenges in Fine-Needle Aspiration and Surgical Pathology Specimens. Am J Clin Pathol 125: S135-S144. 
22. Canberk Ş, Firat P, Schmitt F (2015) Pitfalls in the Cytological Assessment of Thyroid Nodules. Turk Patoloji Derg 31: 18-33.

23. Auger M (2014) Hürthle cells in fine-needle aspirates of the thyroid: a review of their diagnostic criteria and significance. Cancer Cytopathol 122: 241-249.

24. Georgescu R, Oprea AL, Contra A, Hanko OB, Colcer L, et al. (2017) The Sensitivity and Specificity of Fine-Needle Aspiration in Thyroid Neoplasia. J Interdiscip Med 2: 127-131. 